Case Report

\title{
A Large PROP1 Gene Deletion in a Turkish Pedigree
}

\author{
Suheyla Gorar $\left(\mathbb{D},{ }^{1}\right.$ Doga Turkkahraman $\mathbb{D D}^{2},{ }^{2}$ and Kanay Yararbas ${ }^{3}$ \\ ${ }^{1}$ Department of Endocrinology and Metabolism, Antalya Education and Research Hospital, 07100 Antalya, Turkey \\ ${ }^{2}$ Department of Pediatric Endocrinology, Antalya Education and Research Hospital, 07100 Antalya, Turkey \\ ${ }^{3}$ Department of Medical Genetics, Acibadem Mehmet Ali Aydinlar University, 34752 Istanbul, Turkey
}

Correspondence should be addressed to Suheyla Gorar; sgorar@hotmail.com

Received 9 October 2017; Accepted 13 February 2018; Published 14 March 2018

Academic Editor: J. Paul Frindik

Copyright (c) 2018 Suheyla Gorar et al. This is an open access article distributed under the Creative Commons Attribution License, which permits unrestricted use, distribution, and reproduction in any medium, provided the original work is properly cited.

Pituitary-specific paired-like homeodomain transcription factor, PROP1, is associated with multiple pituitary hormone deficiency. Alteration of the gene encoding the PROP1 may affect somatotropes, thyrotropes, and lactotropes, as well as gonadotropes and corticotropes. We performed genetic analysis of PROP1 gene in a Turkish pedigree with three siblings who presented with short stature. Parents were first degree cousins. Index case, a boy, had somatotrope, gonadotrope, thyrotrope, and corticotrope deficiency. However, two elder sisters had somatotroph, gonadotroph, and thyrotroph deficiency and no corticotroph deficiency. On pituitary magnetic resonance, partial empty sella was detected with normal bright spot in all siblings. In genetic analysis, we found a gross deletion involving PROP1 coding region. In conclusion, we report three Turkish siblings with a gross deletion in PROP1 gene. Interestingly, although little boy with combined pituitary hormone deficiency has adrenocorticotropic hormone (ACTH) deficiency, his elder sisters with the same gross PROP1 deletion have no ACTH deficiency. This finding is in line with the fact that patients with PROP1 mutations may have different phenotype/genotype correlation.

\section{Introduction}

The anatomical development of hypothalamic-pituitary-thyroid axis is completed during the first gestational trimester. Transcription factor genes playing a role in the development of hypothalamus and pituitary are pituitary transcription factor 1 (PIT1), Prophet of Pit-1 (PROP1), LIM Homeobox 3 (LHX3), LIM Homeobox 4 (LHX4), and HESX Homeobox 1 (HESX1) which all are known to be important for organ commitment and embryonic pituitary cell differentiation. In case of incomplete differentiation of anterior pituitary gland, one or more of these hormones may be affected, causing combined pituitary hormone deficiency (CPHD) [1]. This condition is mainly sporadic in occurrence, but familial forms have also been described with autosomal recessive, autosomal dominant, and X-linked recessive modes of inheritance. In familial or sporadic CPHD cases, the most common causes are PIT1 and PROP1 gene defects [2].

PROP1 gene is located on chromosome 5q35. Inactivating mutations in PROP1 perturb ontogenesis of pituitary gonadotrophs, somatotrophs, lactotrophs, and thyrotrophs. Somatotropic, thyrotropic, and gonadotropic function impairments manifests clinically as short stature, neonatal hypoglycemia, sequential loss of anterior pituitary tropic hormones [3].

Index case admitted to pediatric endocrinology clinic with complaint of short stature. His family history revealed presence of similar symptoms in his two siblings. Following hormonal examination of the cases, we conducted genetic analyses. PROP1 mutation screening detected a homozygous deletion of the entire PROP1 in three patients.

\section{Case Presentation}

2.1. Case 1: Index Case. A 12.3-year-old male patient was referred to our pediatric endocrinology clinic for evaluation of short stature. He has been using levothyroxine (LT4) for hypothyroidism for more than 2 years. In medical history, he was born at term weighing $3500 \mathrm{~g}$ with uneventful gestation and delivery. His parents were first degree cousins. The height of the mother and the father was 165.5 and $172 \mathrm{~cm}$, respectively. He had three sisters and one brother. His brother and one of the elder sisters were healthy and $175 \mathrm{~cm}$ and $165 \mathrm{~cm}$ tall, respectively. On physical examination, height was $129 \mathrm{~cm}$ (SDS: -3.2) and weight was $28 \mathrm{~kg}$ (body mass index, BMI: 16.8, -1.0 SDS). 
Target height was $175.2 \mathrm{~cm}$ (SDS: -0.2 ). Testicular volume was $2 \mathrm{ml}$ bilaterally with a $3 \mathrm{~cm}$ penile length. Bone age was 9 years. Laboratory findings revealed that free thyroxine (FT4) is $1.2 \mathrm{ng} / \mathrm{dl}$ (N: 0.61-1.57), thyroid stimulating hormone (TSH) is $0.01 \mu \mathrm{IU} / \mathrm{ml}(N$ : $0.37-5)$, thyroid autoantibodies were negative, prolactin (PRL) is $4.5 \mathrm{ng} / \mathrm{ml}(\mathrm{N}: 2.6-13.1)$, adrenocorticotropic hormone (ACTH) is $21.3 \mathrm{pg} / \mathrm{ml}(\mathrm{N}$ : 4.7-48.8), cortisol is $6.8 \mu \mathrm{g} / \mathrm{dl}(N: 6.7-22.6)$, and insulin-like growth factor 1 (IGF-1) is $12.8 \mathrm{ng} / \mathrm{ml}$ ( $N: 85.2-248.8)$. Thyroid ultrasonography revealed a hypoplasic thyroid gland $(1.7 \mathrm{ml})$ with normal parenchyma. On pituitary magnetic resonance (MRI), partial empty sella was detected with normal bright spot (pituitary height was $2.8 \mathrm{~mm}$ ). Clonidine and L.DOPA stimulated peak serum growth hormone $(\mathrm{GH})$ levels were $2.1 \mathrm{ng} / \mathrm{ml}$ and $1.9 \mathrm{ng} / \mathrm{ml}$, respectively. With these results diagnosis of $\mathrm{GH}$ deficiency was confirmed, and recombinant growth hormone $(\mathrm{rGH})$ was initiated. On follow-up, low dose $(1 \mu \mathrm{g})$ ACTH stimulation test was performed, and adrenal deficiency was confirmed (peak cortisol: $12.1 \mu \mathrm{g} / \mathrm{dl}$ ). Then, oral hydrocortisone replacement therapy was initiated (10 mg/m²/day).

At 14.3 years, he was still prepubertal with testicular volume of $3 \mathrm{ml}$ bilaterally. Basal level of testosterone was $<0.01 \mathrm{ng} / \mathrm{ml}$. Then, LHRH stimulation test was performed, and central hypogonadism was confirmed (peak luteinizing hormone, $\mathrm{LH} ; 0.62 \mathrm{mIU} / \mathrm{ml}$, and peak follicle stimulating hormone, FSH; $0.85 \mathrm{mIU} / \mathrm{ml}$ ). Intramuscular depot form of testosterone was initiated, $50 \mathrm{mg} / \mathrm{monthly}$.

2.2. Case 2: 3-Sister Siblings of Index Case. The 22- and 24year-old females who are sisters of index case were referred to our endocrinology outpatient clinic. In their delivery history, they were delivered via spontaneous vaginal birth with uneventful gestation and delivery. They did not present hypoglycemia or respiratory distress during the neonatal period.

At the age of 13, junior sister was diagnosed with $\mathrm{GH}$ deficiency and received $\mathrm{rGH}$ and LT4 replacement therapy for 8 years but the hormonal examination resulting from that period could not be retrieved. Her height and weight measurements were $145 \mathrm{~cm}(-2.83$ SDS) and $37 \mathrm{~kg}$ (BMI: $17.6,-1.7$ SDS), respectively. She was 12 years old at the onset of menarche and was having irregular menstrual cycles with long periods of amenorrhea/oligomenorrhea. There was no axillary/pubic hair, and breast development was Tanner stage II. Her mental function was normal. Bone age was adult, and epiphyseal lines were closed. The ovaries were atrophic on pelvic USG. On pituitary MRI, partial empty sella was detected with normal bright spot (pituitary height was $1.5 \mathrm{~mm}$ ). Her basal hormone levels are shown in Table 1. The patient did not respond to LHRH test (basal FSH was $0.01 \mathrm{mIU} / \mathrm{ml}$ and $\mathrm{LH}$ was $0.11 \mathrm{mIU} / \mathrm{ml}$; peak $\mathrm{FSH}$ was $0.01 \mathrm{mIU} / \mathrm{ml}$ and peak $\mathrm{LH}$ was $0.12 \mathrm{mIU} / \mathrm{ml}$ ). There was no response to thyrotropin releasing hormone (TRH) stimulation test (basal TSH $0.04 \mathrm{mU} / \mathrm{L}$; peak TSH $0.03 \mathrm{mU} / \mathrm{L}$ ). Although sufficient cortisol response was obtained in insulininduced hypoglycemia test, no sufficient GH response was obtained. During hypoglycemia, peak cortisol level was $26 \mu \mathrm{g} / \mathrm{dL}$, while peak $\mathrm{GH}$ level was $0.01 \mathrm{ng} / \mathrm{mL}$. The patient
TABLE 1: Baseline hormone levels of sister siblings.

\begin{tabular}{lcc}
\hline Hormone (normal range) & Sibling 1 & Sibling 2 \\
\hline ACTH $(4,5-48 \mathrm{pg} / \mathrm{ml})$ & 12,5 & 7,5 \\
Kortizol $(6,7-22,6 \mathrm{ug} / \mathrm{dl})$ & 9,82 & 2,34 \\
FSH $(1,2-19,1 \mathrm{mlU} / \mathrm{ml})$ & 0,01 & 0,08 \\
LH $(1,24-8,6 \mathrm{mlU} / \mathrm{ml})$ & 0,01 & 0,04 \\
TSH $(0,34-5,86 \mathrm{ulU} / \mathrm{ml})$ & 0,01 & 0,03 \\
FT4 $(0,61-1,12 \mathrm{ng} / \mathrm{dl})$ & 1,10 & 0,99 \\
Prolactin $(2-15 \mathrm{ng} / \mathrm{ml})$ & 9,12 & 4,43 \\
GH $(0,003-0,971 \mathrm{ng} / \mathrm{ml})$ & 0,02 & 0,01 \\
IGF-1 $(135-449 \mathrm{ng} / \mathrm{ml})$ & 4,11 & 10,62 \\
\hline
\end{tabular}

ACTH: adrenocorticotropic hormone; FSH: follicle stimulating hormone; LH: luteinizing hormone; TSH: thyroid stimulating hormone; FT4: free thyroxine; GH: growth hormone; IGF-1: insulin-like growth factor 1.

was put on LT4, conjugated estrogen, and adult-dose of rGH replacement therapy.

At the age of 15, elder sister was diagnosed with $\mathrm{GH}$ deficiency and central hypothyroidism and has received $\mathrm{rGH}$ and LT4 replacement therapy for 9 years. The hormonal evaluation results from that period could not be retrieved. Height was $154 \mathrm{~cm}(-1.43$ SDS) and weight was $49 \mathrm{~kg}$ (BMI: $20.6,-0.3$ SDS). Her age at onset of menarche was 12 years and her menstruation history was similar to that of her sister. Upon psychiatric evaluation, she had hard time in social interaction and self-expression, and she was found to have borderline intelligence with an Intelligence Quotient Test (IQT) score of 80 . Her bone age was adult, and epiphyseal lines were closed. Ovaries were atrophic on pelvic USG. On pituitary MRI, partial empty sella was detected with normal bright spot (pituitary height was $2.5 \mathrm{~mm}$ ). Basal hormone levels are given Table 1. The patient did not respond to the LHRH test (basal FSH $0.08 \mathrm{mIU} / \mathrm{ml}$ and $\mathrm{LH}$ $0.09 \mathrm{mIU} / \mathrm{ml}$; peak FSH $0.09 \mathrm{mIU} / \mathrm{ml}$ and $\mathrm{LH} 0.11 \mathrm{mIU} / \mathrm{ml}$ ). Additionally, there was no response to TRH stimulation test (basal TSH $0.01 \mathrm{mU} / \mathrm{L}$; peak TSH $0.01 \mathrm{mU} / \mathrm{L}$ ). During insulin-induced hypoglycemia test, maximum cortisol level was measured as $19.5 \mathrm{mg} / \mathrm{dL}$, and growth hormone level was $0.01 \mathrm{ng} / \mathrm{mL}$. With these findings, the case was put on LT4, conjugated estrogen, and adult doses of rGH replacement therapy.

2.3. Genetic Analysis. Genomic DNA of the family members was extracted according to the manufacturer's standard procedure using the QIAamp DNA Blood Midi Kit (Qiagen, Hilden, Germany). The DNA samples were quantified with a nanophotometer (Implen, Germany) and used at a concentration of $50 \mathrm{ng} / \mu \mathrm{L}$. PROP1 gene was amplified using PCR primers: Forward ( $5^{\prime}$ ACCTACACACACATTCAGAGAC $3^{\prime}$ ), Reverse (5' TGGAGCCTATGCTTTCAGC $3^{\prime}$ ), Forward ( $5^{\prime}$ AAAGACTGGAGCAGCACAGG3 ${ }^{\prime}$ ), Reverse (5' GGTGGTGAGATGAGGCCTGT $3^{\prime}$ ), and Forward $\left(5^{\prime}\right.$ GCCTTGTGGAAGAGCTTTACTCC $3^{\prime}$ ), Reverse (5' CACCATGCATCTGCTTCACCC $3^{\prime}$ ). PCRs were validated by using 2\% agarose gel electrophoresis (Fermentas, Lituenia). PCRs for each individual were mixed to obtain PCR pools, purified and quantified. 


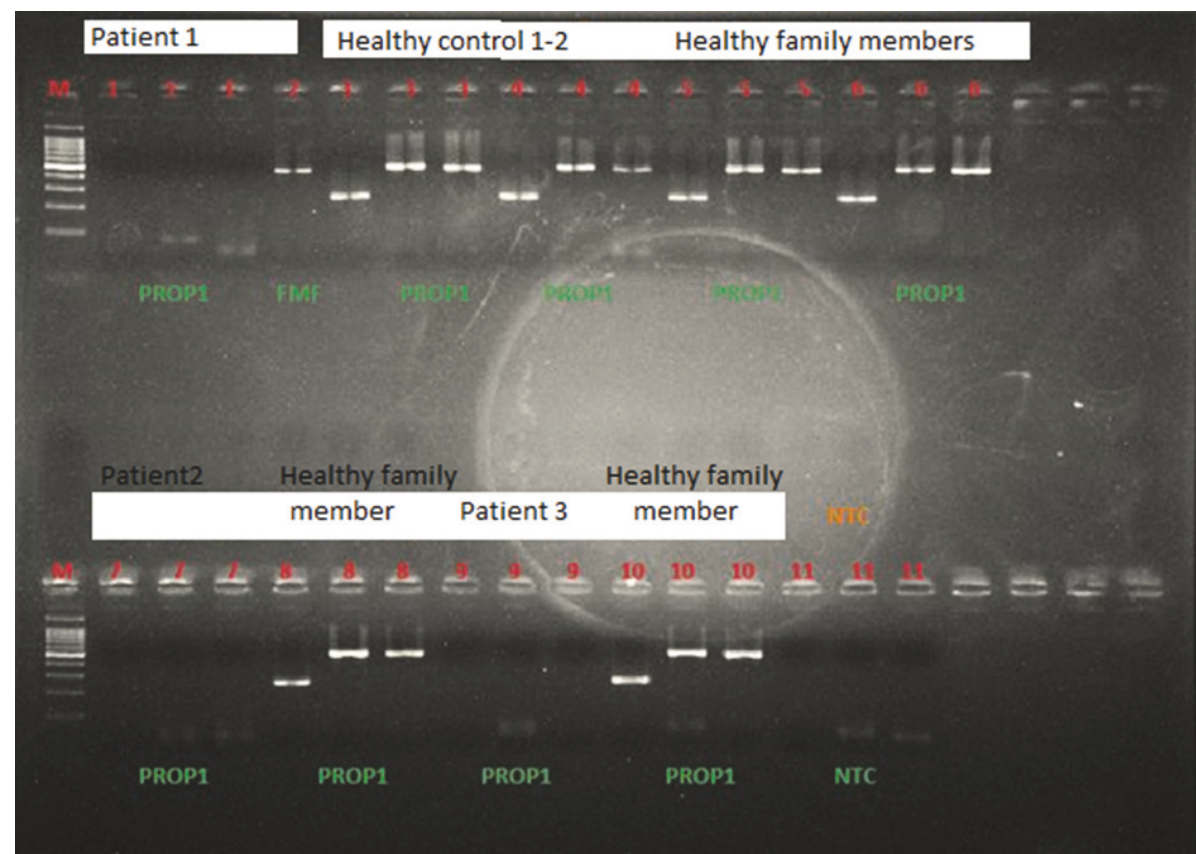

FIGURE 1: Three patients showed no amplification in PROP1 locus, whereas reference gene (Mediterranean fever-MEFV) was amplified. Healthy controls and healthy family members showed successful amplifications either.

Purifications were done by using exosap purification program (ExoSAP-IT, Affymetrix Inc., USA). Second Sephadex column (Sigma, Germany) was used for the PCR purification. Gel electrophoresis revealed no amplification of the gene, so in order confirm a possible gross deletion, healthy controls were tested for the same gene, as well as healthy family members. In addition Mediterranean fever (MEFV) gene amplification was performed simultaneously as reference amplification. MEFV amplification was successful in all patients. On behalf of these results, gross deletion involving PROP1 coding region was concluded as disease causing mutation in these patients (Figure 1).

\section{Discussion}

Genetic aetiologies of isolated pituitary hormone deficiency or CPHD have been researched for many years. CPHD occurs due to recognized mutations of transcription factors such as HESX1, PROP1, POU1F1, LHX3, and LHX4. PROP1 mutations represent the most common known genetic defect of both familial and sporadic CPHD. Phenotypic characteristics may be variable in CPHD result from these transcription factors' mutations, including PROP1. Published case reports, population studies, and reviews on genetic analysis of CPHD have shown new genetic variations, differences in the severity of the hormonal deficits, and the time of onset. As a result from clinical and hormonal phenotype highly variable [4-6], general properties of PROP1 mutation are a clinical disorder where GH deficiency is observed together with one or more anterior pituitary hormone deficiencies. The main clinical symptom is growth retardation with an onset during infancy or early childhood. Hypothyroidism is often mild and develops during late infancy or childhood. The affected individuals are not expected to be infertile, but their secondary sexual development can be delayed and incomplete. Untreated men generally have smaller testes and penis. Some of the affected women have menstrual bleeding, but may often require hormone replacement therapy afterwards. ACTH deficiency is less common but may also be seen, which usually develops during adolescence or adulthood [6]. PROP1 deficiency was first discovered among Ames mice which clinically results in dwarf mice with CPHD. The most common pituitary hormone deficiencies are of GH, TSH, FSH, LH, and PRL, while ACTH deficiency is also observed, though rarely [3].

It was shown that deletion of PROP1 in mice causes severe pituitary hypoplasia with failure of the entire PIT1 lineage and delayed gonadotrope development. Pituitary hormone deficiencies caused secondary endocrine problems and a high rate of perinatal mortality due to respiratory distress. Lung atelectasis in mutants correlated with reduced levels of NKX2.1 (TITF1; 600635) and surfactant (SFTPA1; 178630). Lethality of mice homozygous for either the null allele or a spontaneous hypomorphic allele was strongly influenced by genetic background [7]. As further human studies included familial total deletions of the gene all causing CPHD phenotype, gross deletions became well characterized in Human Gene Mutation Database (HGMD) as disease causing mutations $[2,8-11]$. PROP1 spans less than $4 \mathrm{~kb}$ of genomic DNA; no benign copy number or deletion variations are defined in Decipher or Genomic Variant Database (DGV). The extent of the reported deletions was variable but all totally covered the PROP1 gene. This is the sixth report of gross PROP1 deletion worldwide. No further information about the deletion is available in this family since high resolution array was not performed. Deletions were detected 
by PCR gel electrophoresis. Amplification was obtained in obligate heterozygote carriers and since the reactions were performed with reference genes and healthy controls, no further confirmatory test was performed.

In this study, we presented the hormonal and genetic evaluations of three siblings having PROP1 deletion. Interestingly, although little boy with CPHD has ACTH deficiency, her elder sisters with the same gross PROP1 deletion have no ACTH deficiency. Peak cortisol levels of elder sisters were considered adequate in insulin-induced hypoglycemia test $[12,13]$. Also, they were stable in terms of clinical and biochemical status. But, clinical and hormonal evaluations of cases were continued follow-up because of possible adrenal insufficiency in adulthood period. This finding is in line with the fact that patients with PROP1 mutations definitely may have different phenotype/genotype correlation. Deladoëy et al. [14] studied 36 families with a total of 73 affected patients with CPHD. They demonstrated, based on a great variability in phenotype, the secretion of pituitary-derived hormones ( $\mathrm{GH}, \mathrm{TSH}, \mathrm{LH}$, and $\mathrm{FSH}$ ) decline gradually with age, following a different pattern and time scale in each individual. On the other hand, seven patients presented low basal levels of cortisol and ACTH, but stimulated levels after insulin-induced hypoglycemia revealed no abnormality. None of the patients were on cortisol replacement therapy. Similarly, et al. [15] showed that two siblings with PROP1 mutation who presented with short stature have not corticotropin deficiency. In a multicentric study conducted by Vallette-Kasic et al. [16] in France, 27 unrelated families originated from five different countries screened for PROP1 gene anomalies. Patients were included on the basis of GH deficiency associated with at least one other pituitary hormone deficiency. Cortisol was initially found normal in all patients, but late onset ACTH deficiency was observed in four patients. In insulin-induced hypoglycemia test, two patients were blunted cortisol response and given cortisol replacement therapy. As a result, they emphasized that corticotroph deficiency was frequently observed in association with GH, $\mathrm{TSH}$, and gonadotropin deficiency in PROP1 gene alteration and should be carefully sought during follow-up. In another study, discussed by Reynaud et al. [17], genetic screening was performed in 195 patients with combined pituitary hormone deficiency. In 109 patients without extrapituitary abnormalities, 20 had PROP1 mutations, including eight patients with a family history of CPHD. Eighteen of 20 patients carried PROP1 mutations had gonadotroph and somatotroph deficiency at postpubertal age, while two patients had corticotroph, thyrotroph, and somatotroph deficiency at pubertal age.

In conclusion, PROP1 gene has maintenance role in five types of principal anterior pituitary hormone-secreting cells, which are somatotroph, lactotroph, thyrotroph, gonadotroph, and corticotroph, basis, and their differentiation progress. But, in human trials different mutations that cause CPHD in the PROP1 gene have been shown $[2,5]$. Variability of mutations and deletions in PROP1 gene can cause different types of hormone deficiency. This state is very important for therapy and follow-up of the patients.

\section{Disclosure}

Suheyla Gorar is the corresponding and primary author of this report.

\section{Conflicts of Interest}

The authors declare that there are no conflicts of interest regarding the publication of this paper.

\section{Authors' Contributions}

Index case and his siblings were evaluated, diagnosed, and treated by Doga Turkkahraman and Suheyla Gorar, respectively. Kanay Yararbas analyzed and interpreted the patient's genetic data. All authors read and approved the final paper.

\section{References}

[1] D. Kelberman and M. T. Dattani, "Hypopituitarism oddities: congenital causes." Hormone Research, vol. 68, pp. 138-144, 2007.

[2] M. G. Abrão, M. V. Leite, L. R. Carvalho et al., "Combined pituitary hormone deficiency (CPHD) due to a complete PROP1 deletion," Clinical Endocrinology, vol. 65, no. 3, pp. 294-300, 2006.

[3] C. Asteria, J. H. A. Oliveira, J. Abucham, and P. Beck-Peccoz, "Central hypocortisolism as part of combined pituitary hormone deficiency due to mutations of PROP-1 gene," European Journal of Endocrinology, vol. 143, no. 3, pp. 347-352, 2000.

[4] L. Brunerova, I. Cermakova, B. Kalvachova, J. Skrenkova, R. Poncova, and P. Sedlak, "Therapy-induced growth and sexual maturation in a developmentally infantile adult patient with a PROP1 Mutation," Frontiers in Endocrinology, vol. 8, 2017.

[5] M. Elizabeth, A. C. S. Hokken-Koelega, J. Schuilwerve et al., "Genetic screening of regulatory regions of pituitary transcription factors in patients with idiopathic pituitary hormone deficiencies," Pituitary, vol. 21, pp. 76-83, 2018.

[6] M. Giordano, "Genetic causes of isolated and combined pituitary hormone deficiency," Best Practice \& Research Clinical Endocrinology \& Metabolism, vol. 30, no. 6, pp. 679-691, 2016.

[7] I. O. Nasonkin, R. D. Ward, L. T. Raetzman et al., "Pituitary hypoplasia and respiratory distress syndrome in Propl knockout mice," Human Molecular Genetics, vol. 13, no. 22, pp. 2727$2735,2004$.

[8] D. Kelberman, J. P. G. Turton, K. S. Woods et al., "Molecular analysis of novel PROP1 mutations associated with combined pituitary hormone deficiency (CPHD)," Clinical Endocrinology, vol. 70, no. 1, pp. 96-103, 2009.

[9] A. Akcay, K. Ulucan, N. Taskin et al., "Suprasellar mass mimicking a hypothalamic glioma in a patient with a complete PROP1 deletion," European Journal of Medical Genetics, vol. 56, no. 8, pp. 445-451, 2013.

[10] K. Hemchand, K. Anuradha, S. Neeti et al., "Entire prophet of Pit-1 (PROP-1) gene deletion in an Indian girl with combined pituitary hormone deficiencies," Journal of Pediatric Endocrinology and Metabolism, vol. 24, no. 7-8, pp. 579-580, 2011.

[11] H. Zhang, Y. Wang, L. Han, X. Gu, and D. Shi, "A large deletion of PROP1 gene in patients with combined pituitary hormone deficiency from two unrelated Chinese pedigrees," Hormone Research in Paediatrics, vol. 74, no. 2, pp. 98-105, 2010. 
[12] S. R. Bornstein, B. Allolio, W. Arlt et al., "Diagnosis and treatment of primary adrenal insufficiency: an endocrine society clinical practice guideline," The Journal of Clinical Endocrinology \& Metabolism, vol. 101, no. 2, pp. 364-389, 2016.

[13] Y. Simsek, Z. Karaca, F. Tanriverdi, K. Unluhizarci, A. Selcuklu, and F. Kelestimur, "A comparison of low-dose ACTH, glucagon stimulation and insulin tolerance test in patients with pituitary disorders," Clinical Endocrinology, vol. 82, no. 1, pp. 45-52, 2015.

[14] J. Deladoëy, C. Flück, A. Büyükgebiz et al., "Hot spot in the PROP1 gene responsible for combined pituitary hormone deficiency," The Journal of Clinical Endocrinology \& Metabolism, vol. 84, no. 5, pp. 1645-1650, 1999.

[15] T. C. Vieira, M. R. Dias da Silva, J. M. Cerutti et al., "Familial combined pituitary hormone deficiency due to a novel mutation R99Q in the hot spot region of Prophet of Pit-1 presenting as constitutional growth delay," The Journal of Clinical Endocrinology \& Metabolism, vol. 88, no. 1, pp. 38-44, 2003.

[16] S. Vallette-Kasic, A. Barlier, C. Teinturier et al., "PROP1 gene screening in patients with multiple pituitary hormone deficiency reveals two sites of hypermutability and a high incidence of corticotroph deficiency," The Journal of Clinical Endocrinology \& Metabolism, vol. 86, no. 9, pp. 4529-4535, 2001.

[17] R. Reynaud, M. Gueydan, A. Saveanu et al., "Genetic screening of combined pituitary hormone deficiency: Experience in 195 patients," The Journal of Clinical Endocrinology \& Metabolism, vol. 91, no. 9, pp. 3329-3336, 2006. 


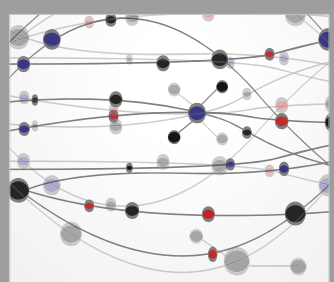

The Scientific World Journal
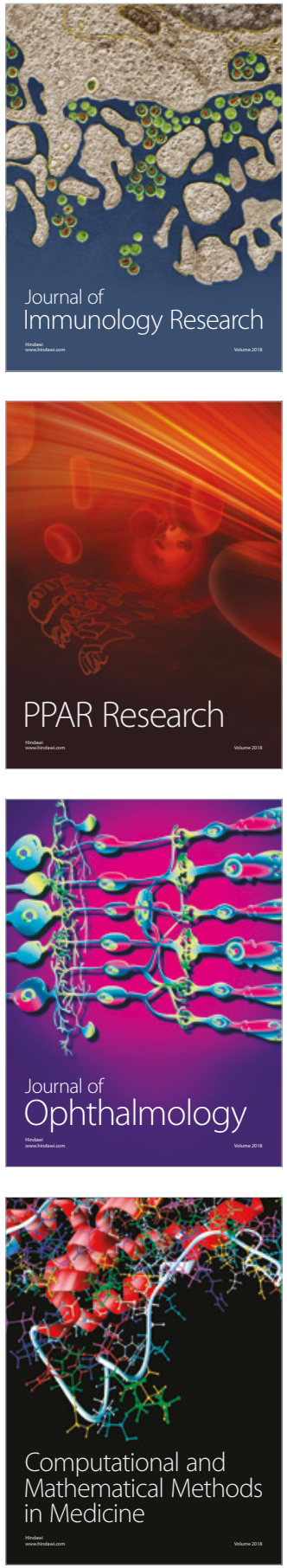

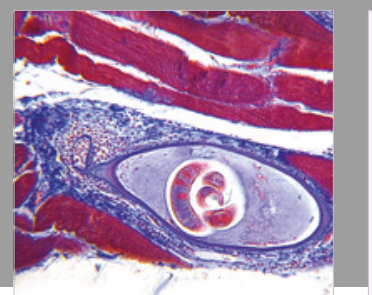

Gastroenterology Research and Practice

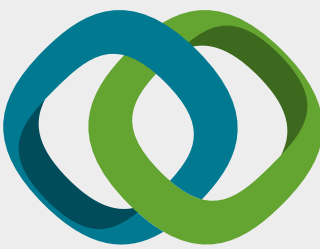

\section{Hindawi}

Submit your manuscripts at

www.hindawi.com
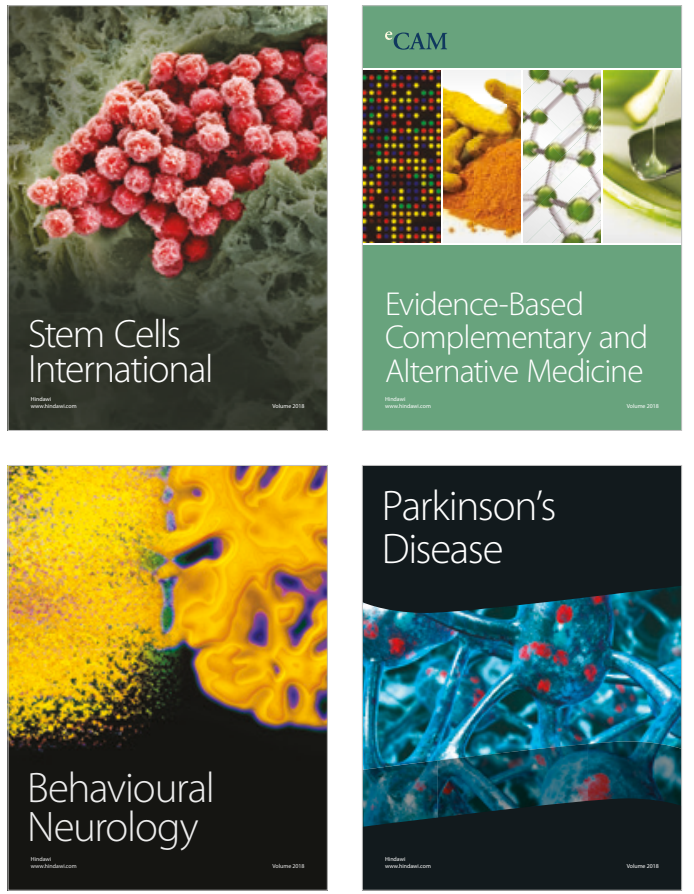

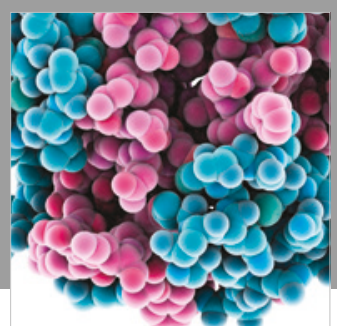

ournal of

Diabetes Research

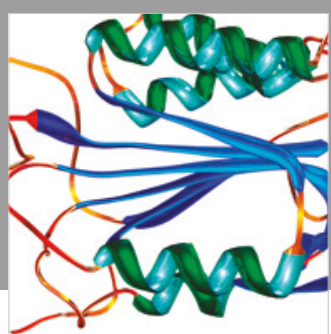

Disease Markers
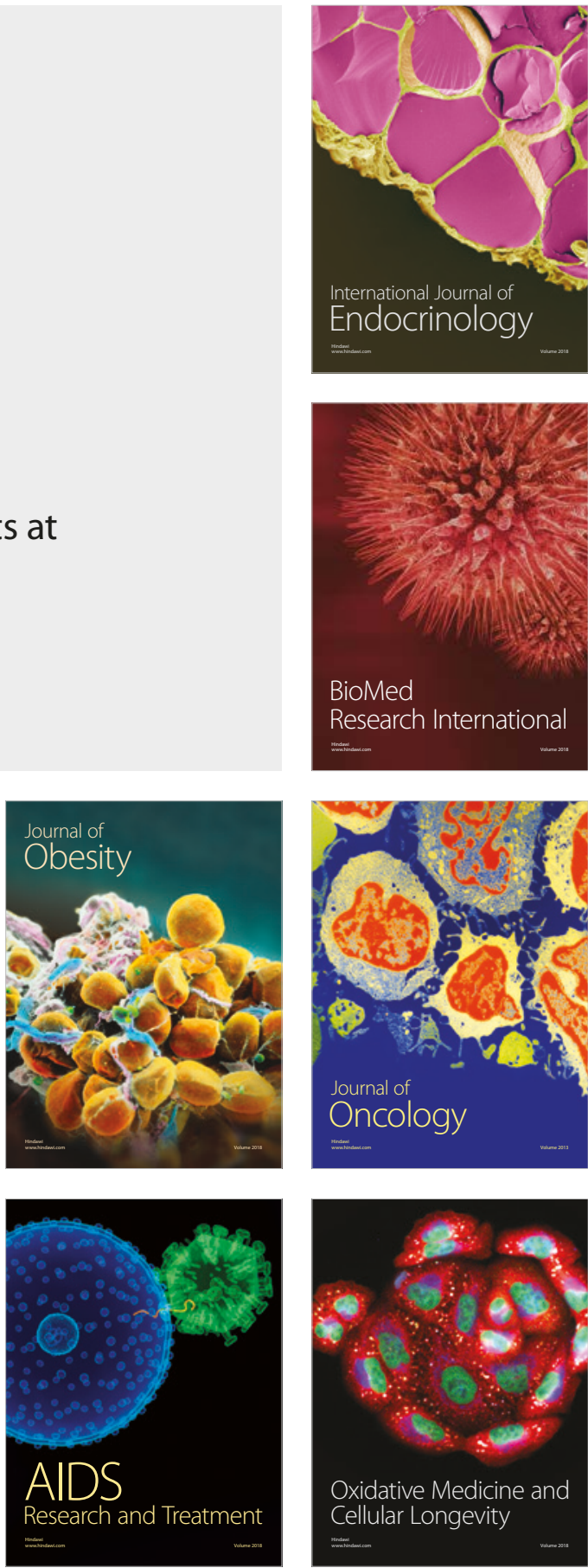